\title{
Biliary neuroendocrine tumor (BNET) of hepatic hilum: An interesting presentation with obstructive jaundice
}

\author{
J. M. V. Amarjothi, O. L. Naganath Babu, J. Livin Jose, \\ Bennet Duraisamy, S. Rajendran
}

\begin{abstract}
Biliary neuroendocrine tumour (BNET) are rare tumours of the biliary system. They may present with obstructive jaundice and resemble cholangiocarcinomas. However, they have good prognosis if resected completely. The aim of this article is to show the presentation of BNET in a young female, its biological behavior, its newer immunotyping for precise diagnosis and possibility of complete surgical excision which can result in excellent prognosis.
\end{abstract}

Keywords: Biliary neuroendocrine tumor, Hilar mass, Neuroendocrine tumour, Obstructive jaundice

\section{How to cite this article}

Amarjothi JMV, Babu OLN, Jose JL, Duraisamy B, Rajendran S. Biliary neuroendocrine tumor (BNET) of hepatic hilum: An interesting presentation with obstructive jaundice. Int $\mathrm{J}$ Case Rep Images 2018;9:100922Z01JA2018.

Article ID: 100922Z01JA2018

J. M. V. Amarjothi ${ }^{1}$, O. L. Naganath Babu ${ }^{1}$, J. Livin Jose ${ }^{1}$ Bennet Duraisamy ${ }^{1}$, S. Rajendran ${ }^{1}$

Affiliations: ${ }^{1}$ Department of Surgical Gastroenterology, Madras Medical College, Chennai, India.

Corresponding Author: Dr. J. M. V. Amarjothi, Department of Surgical Gastroenterology, Madras Medical College, Chennai-600003, India; Email: drmosesvikramamarjothi@hotmail.com

Received: 13 April 2018

Accepted: 12 May 2018

Published: 20 June 2018 doi: 10.5348/100922Z01JA2018CR

\section{INTRODUCTION}

Biliary neuroendocrine tumours are rare tumours of the biliary hilum and can present clinically just like hilar cholangiocarcinomas. These are seen in middle aged females more commonly involving the common hepatic duct and proximal ducts and have an insidious and less aggressive clinical course when compared to cholangiocarcinoma [1]. These tumours should be differentiated from other hilar tumors as they are associated with markedly better prognosis on Ro resection.

\section{CASE REPORT}

Thirty year old female presented with jaundice, pruritus and clay colored stools for three months.Contrast enhanced Computerised Tomography (CECT) (Figure 1) and Magnetic Resonance CholangioPancreaticography (MRCP) revealed a non cirrhotic liver with abrupt cut off of the common hepatic duct with Intrahepatic Biliary Radicle Dilatation (IHBR), right and left hepatic duct dilatation with hilar mass of size $3 \times 3 \mathrm{~cm}$ suggestive of Type 1 cholangiocarcinoma (Figure 2). Fine Needle Aspiration Cytology (FNAC) of the mass lesion was suggestive of malignancy. As the patient developed features of cholangitis and had increased bilirubin, Percutaneous transhepatic biliary drainage (PTBD) of the left system was done. After PTBD, the laboratory investigations showed normalization of liver function (Total Bilirubin-1.2 mg\%, Direct bilirubin-0.6 mg\%, Alkaline Phosphatase- $80 \mathrm{IU} / \mathrm{ml}$ ) and tumor markers (Alpha-FetoProtein level (AFP)-3.5 ng\%, CA 19-9- 25 $\mathrm{IU} / \mathrm{ml}$ and CEA- $2.5 \mathrm{ng} \%)$. After normalization of liver function, patient was planned for elective surgery. The hilar mass was in close proximity to the portal vein and carefully delineated and then resection of the hilar mass with roux en y hepaticojejunostomy was done. HPE of the 


\section{EDORIUM Journals}

specimen was suggestive of low grade neuroendocrine tumour of the hilum with clear margins (Figure 3). Immunohistochemistry (IHC) done showed cytokeratin 7, chromogranin positive, neuron specific enolase strong immunoreactivity (70\%) and CK 20, CD 34 negativity (Figures 4 and 5).

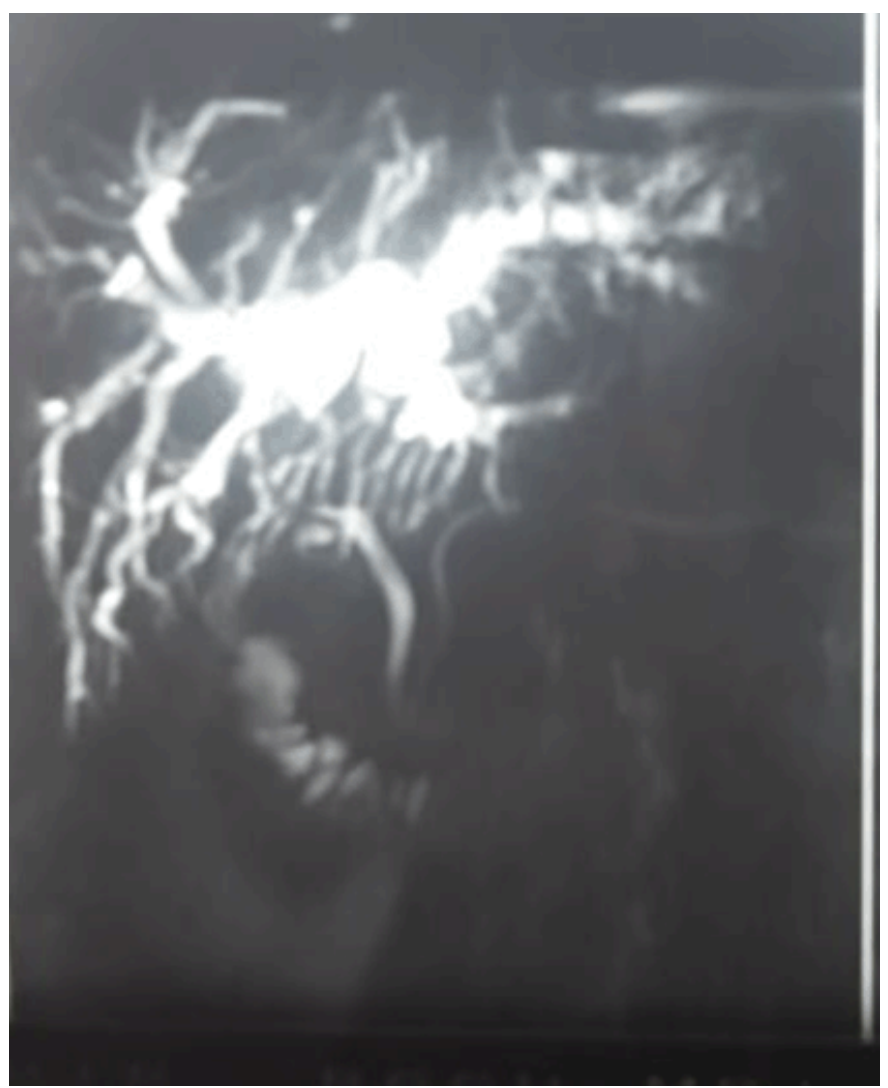

Figure 1: MRCP showing dilated Bilateral IHBR with abrupt cut off.

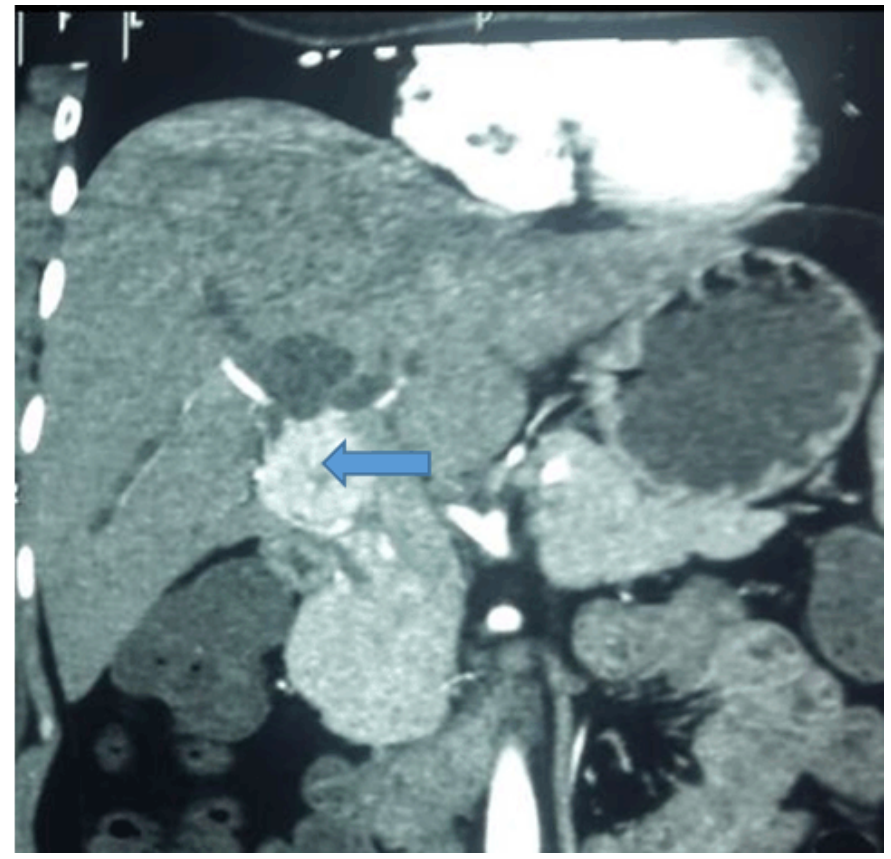

Figure 2: CECT showing hilar mass (arrow) with upstream bilateral dilated IHBR

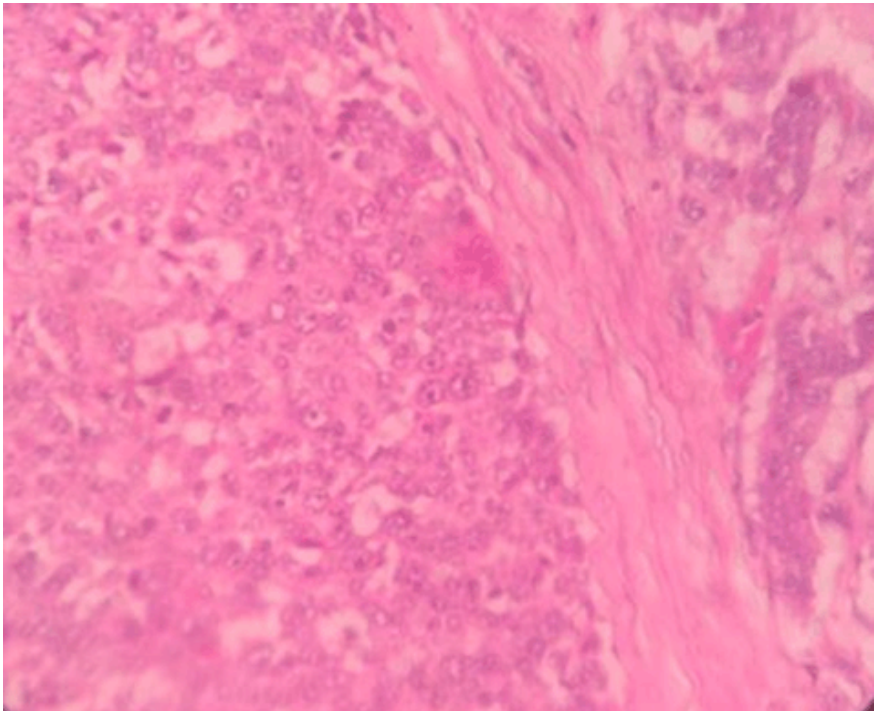

Figure 3: Cords and nests of tumour cells with moderate eosinophilic cytoplasm, round to oval nuclei and stippled chromatin with moderate pleomorphism and prominent nucleoli (H\&E stain, x100).

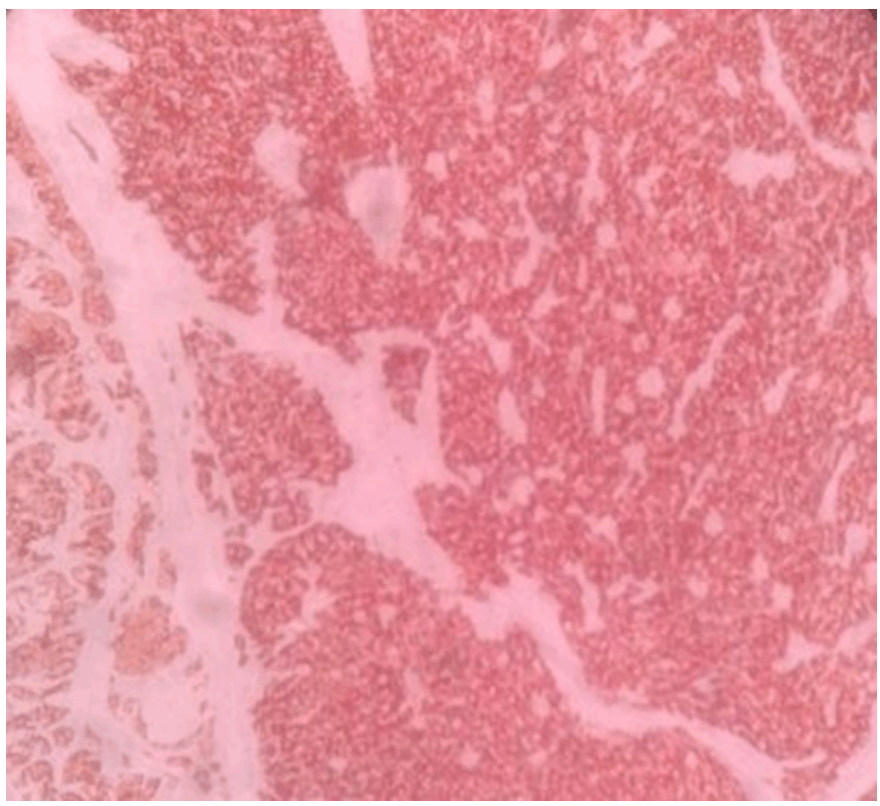

Figure 4: IHC tumour cells diffusely staining for Chromogranin (H\&E stain, x100).

The patient had an unremarkable postoperative course and was discharged home on postoperative Day 11 after free flow of contrast was seen throught the hepaticojejunostomy site when contrast was given through the retained PTBD in the left hepatic duct. The case is described to emphasize that BNET (Biliary Neuro Endocrine Tumours) can present as hilar masses and it must be thought as a entertained diagnosis in spite of its rarity. 


\section{EDORiUM Journals}

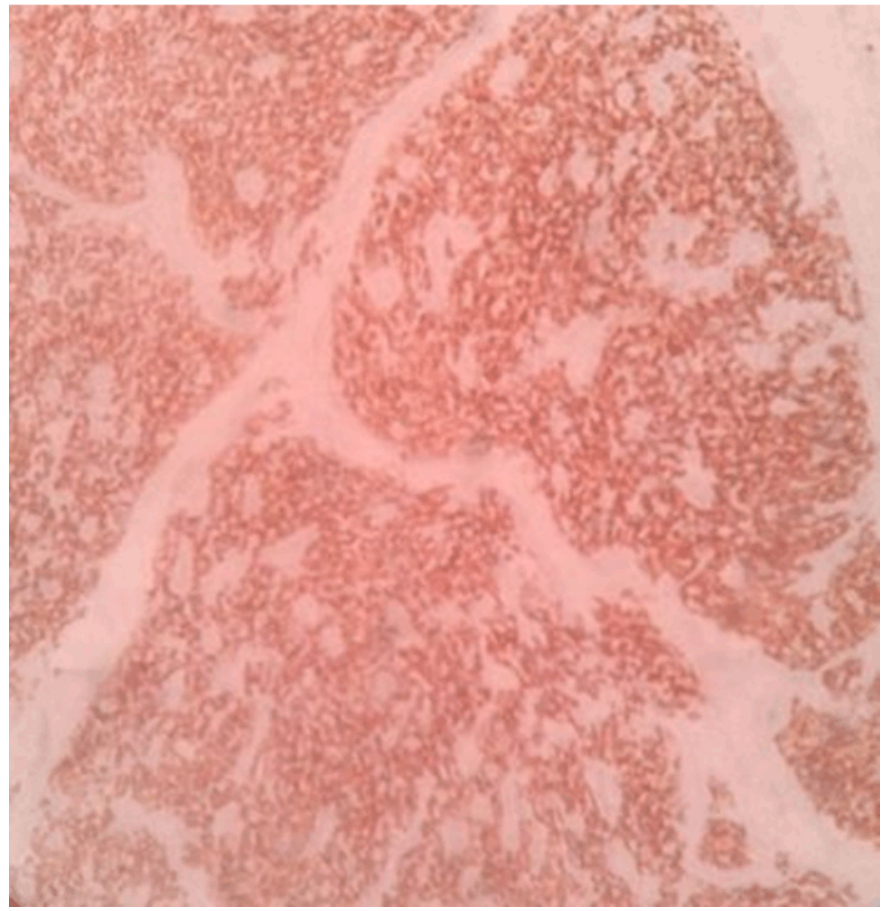

Figure 5: IHC tumour cells diffusely staining for CK 7 (H\&E stain, x100).

\section{DISCUSSION}

World Health Organization (WHO) system distinguishes well-differentiated neuroendocrine tumors (NETs) from poorly differentiated neuroendocrine carcinomas (NECs) [2, 3]. Well differentiated NETs, or carcinoid tumors, are those with mild or no atypia, $\leq 1 \mathrm{~cm}$ in size, with $\leq 2$ mitoses/10HPFs and without angioinvasion. Poorly differentiated neuroendocrine carcinomas (NECs) have high grade metastatic potential and are composed of highly atypical, small to intermediate sized tumor cells with necrosis and prominent angio and/ or perineural invasion.

The European Neuroendocrine Tumor Society (ENETS) grades NET into three categories (G1-3) that dependent upon the tumor's proliferation status. G1 tumors have $<2$ mitoses/10 HPFs, or a Ki-67 index less than 2\%. G2 tumors have 2-20 mitoses/10 HPFs, or a Ki-67 index between 3 and 20\%. G3 tumors have $>21$ mitoses/10 HPFs, and a Ki-67 index greater than 20\% [2, $3]$.

NETs arising from the biliary tract are extremely rare (0.32\%) [4]. In an analysis of 150 cases, most are found in the common hepatic duct and proximal bile duct $(19.2 \%)$, followed by the middle of the common bile duct (17.9\%) and cystic duct (16.7\%) [1]. Symptoms related to hormone or peptide secretion are seen in $<10 \%$ of cases. BNET are more common in females (F:M ratio of 1.6:1) at a mean age of approximately 47 years(range 6-79 years)where the most common symptoms were jaundice (60.3\%) and pruritus (19.2\%) [1]. Cholelithiasis co-existed in 15 cases (19.2\%). Surgical management was considered the main treatment for extrahepatic BNETs, where excision of extrahepatic biliary tree (62.82\%) with portal vein lymphadenectomy (43.6\%) was the most popular procedure [1]. BNETs are extremely rare which makes their characterization particularly difficult. Biliary NET are diagnosed if it fulfilled the following diagnostic criteria: (1) radiologically primary tumour in the extrahepatic biliary apparatus (2) classic pathology of neuroendocrine tumour with the histology of trabecular rosette, nesting, insular, or ribbon-like cell clusters, variable mitotic activity with small cell or large cell cytological features (3) positive expression of more than one type of immunohistochemical stain, such as chromogranin A, synaptophysin, CD 56 (CD56) or neural cell adhesion molecule [5].

In clinical practice, these lesions are difficult to diagnose and distinguish from cholangiocarcinoma preoperatively. Certain clinical features like propensity for young age, benign local invasion or distant metastatic disease can be useful but these are not absolute in distinguishing BNET from adenocarcinoma. Wellcircumscribed hypervascular tumor during the arterial phase may help to differentiate them from other biliary neoplasms [6].

A pre-operative diagnosis can be made by examining brush cytology [7] Somatostatin analogues such as octreotide, have been shown in clinical trials cause symptomatic improvement [8]. Prognostic data for BNETs are limited due to their rarity [9].

It is to be noted that BNETs were previously classified as small cell carcinoma[SCC] and their prognosis shows marked heterogeneity. Albores-Saavedra et al., [10] analyzed the demographics and 10-year relative survival rates of carcinoids and small cell carcinomas [SCCs] of the gallbladder and ExtraHepatic Bile Duct[EHBD] according to histologic type and stage. There were 31 carcinoid tumors and 17 SCCs of the EHBD. The 10year survival rate was $80 \%$ for carcinoid tumors of the EHBD And o\% for SCC of the EHBD. Almost all patients with SCC in the biliary system died within one year after diagnosis implying that carcinoids have better prognosis.

The optimal treatment for patients with NET or NEC is controversial as most of the current literature available comes from case reports and small case series, without comparable control groups [11]. Options for the management of localized biliary NETs include complete surgical resection, systemic therapy and multivisceral transplant.

\section{CONCLUSION}

BNETS are rare tumors in the biliary tract which may mimic cholangiocarcinoma. However, these have good prognosis when identified early and resected. Further developments in the techniques of immunohistochemistry is in order to precisely diagnose and treat these rare neoplasms. 


\section{EDORiUM Journals}

\section{REFERENCES}

1. Michalopoulos N, Papavramidis TS, Karayannopoulou G, Pliakos I, Papavramidis ST, Kanellos I. Neuroendocrine tumors of extrahepatic biliary tract. Pathol Oncol Res 2014 Oct;20(4):765-75.

2. Bosman FT. WHO Classification of Tumor of the Digestive System. Lyon: IARC Press; 2010.

3. Rindi G, Klöppel G, Alhman H, et al. TNM staging of foregut (neuro)endocrine tumors: A consensus proposal including a grading system. Virchows Arch 2006 Oct;449(4):395-401.

4. Hosoda K, Kobayashi A, Shimizu A, et al. Neuroendocrine tumor of the common bile duct. Surgery 2016 Aug;16o(2):525-6.

5. Kim J, Lee WJ, Lee SH, et al. Clinical features of 20 patients with curatively resected biliary neuroendocrine tumours. Dig Liver Dis 2011 Dec;43(12):965-70.

6. Raspanti C, Falco N, Silvestri V, Rotolo G, Bonventre S, Gulotta G. Neuroendocrine tumor of the common bile duct: Case report. G Chir 2016 Nov-Dec;37(6):27580 .

7. Noronha YS, Raza AS. Well-differentiated neuroendocrine (carcinoid) tumors of the extrahepatic biliary ducts. Arch Pathol Lab Med 2010 Jul;134(7):1075-9.

8. Oberg KE, Reubi JC, Kwekkeboom DJ, Krenning EP. Role of somatostatins in gastroenteropancreatic neuroendocrine tumor development and therapy. Gastroenterology 2010 Sep;139(3):742-53.e1.

9. Oshiro $\mathrm{Y}$, Gen R, Hashimoto S, Oda T, Sato T, Ohkohchi N. Neuroendocrine carcinoma of the extrahepatic bile duct: A case report. World J Gastroenterol 2016;22:6960-4.

10. Albores-Saavedra J, Batich K, Hossain S, Henson DE, Schwartz AM. Carcinoid tumors and smallcell carcinomas of the gallbladder and extrahepatic bile ducts: A comparative study based on 221 cases from the surveillance, epidemiology, and end results program. Ann Diagn Pathol 2009 Dec;13(6):378-83.

11. Gaujoux S, Sauvanet A, Belghiti J. Place of surgical resection in the treatment strategy of gastrointestinal neuroendocrine tumors. Target Oncol 2012 Sep;7(3) :153-9.

$$
* * * * * * * * *
$$

\section{Author Contributions}

J. M. V. Amarjothi - Substantial contributions to conception and design, Acquisition of data, Analysis and interpretation of data, Drafting the article, Revising it critically for important intellectual content, Final approval of the version to be published

O. L. Naganath Babu - Substantial contributions to conception and design, Acquisition of data, Analysis and interpretation of data, Drafting the article, Revising it critically for important intellectual content, Final approval of the version to be published

J. Livin Jose - Substantial contributions to conception and design, Acquisition of data, Analysis and interpretation of data, Drafting the article, Revising it critically for important intellectual content, Final approval of the version to be published

Bennet Duraisamy - Substantial contributions to conception and design, Acquisition of data, Analysis and interpretation of data, Drafting the article, Revising it critically for important intellectual content, Final approval of the version to be published

S. Rajendran - Substantial contributions to conception and design, Acquisition of data, Analysis and interpretation of data, Drafting the article, Revising it critically for important intellectual content, Final approval of the version to be published

\section{Guarantor of Submission}

The corresponding author is the guarantor of submission.

\section{Source of Support}

None

\section{Consent Statement}

Written informed consent was obtained from the patient for publication of this case report.

\section{Conflict of Interest}

Authors declare no conflict of interest.

\section{Copyright}

(C) $2018 \mathrm{~J}$. M. V. Amarjothi et al. This article is distributed under the terms of Creative Commons Attribution License which permits unrestricted use, distribution and reproduction in any medium provided the original author(s) and original publisher are properly credited. Please see the copyright policy on the journal website for more information. 
Access full text article on other devices

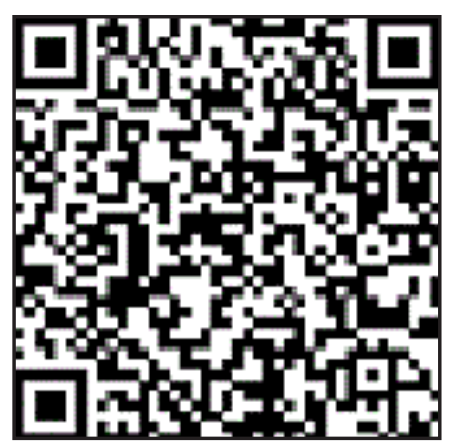

Access PDF of article on other devices

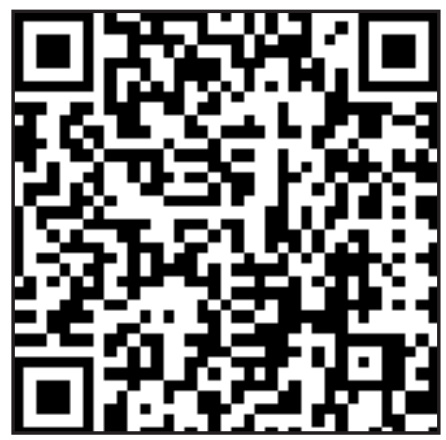

